\title{
Surfando com James Joyce e Dorothy Lamour... Paisagens sonoras, imaginário polinésio e o processo composicional de Gilberto Mendes
}

Heloísa de Araújo Duarte Valente

Resumo: Na obra de Gilberto Mendes (1922-2016) verifica-se uma prática incessante de interfaces com as linguagens do cinema, da literatura, do teatro, da publicidade, dentre outros. A Polinésia em sua representação hollywoodiana da década de 1930 é tema frequente. Este cenário é construído, com base em elementos presentes no código musical, provenientes da estética vienense. Mendes assimilará essa estética em sua obra. Na década de 1950, eclode a cultura tiki pop e sua paisagem sonora correspondente, representada por Martin Denny. Pretende-se apontar as mutações do paraíso longínquo e o papel da música na sua composição.

Palavras-Chave: Gilberto Mendes; música polinésia; paisagem sonora; cultura tiki pop; música de cinema.

Abstract: Surfing with James Joyce and Dorothy Lamour. Soundscapes, the Polynesian imaginary and the compositional process of Gilberto Mendes - In the work of Gilberto Mendes (1922-2016) there is an incessant practice of interfaces with the languages of cinema, literature, theater, advertising, among others. Polynesia, in its 1930s Hollywood representation is a frequent subject. This scene is constructed, from elements presented in the musical code, coming from Viennese aesthetics. Mendes will assimilate this aesthetic in his own work. In the 1950s, the culture of tiki pop emerges, as well as its soundscape created by Martin Denny. It is intended to point out the distant paradise transformations and the role of music in his composition.

Keywords: Gilberto Mendes; Polynesian music; soundscape; tiki pop culture; film music. 


\section{Vivendo sua música...}

Acima de tudo, é preciso viver a música.

A que fazemos, a que ouvimos.

A música que abre um mundo dentro de nós. O mundo dos signos, de toda uma época, de um momento fugaz, de um modo de pensar, de um acontecimento, um lugar, uma paixão...

Estas são as últimas frases de Viver sua música, segundo livro de memórias intelectuais de Gilberto Mendes (1922-2016). Flâneur cosmopolita, atravessou a modernidade e a pós-modernidade. Inicialmente orientado pela estética nacionalista, a partir da década de 1960, tornou-se um experimentador radical ao explorar, de maneira muito peculiar, o repertório fixado pela cultura do que se usava denominar mass media'. Esta será matériaprima de composições marcantes do período. O vivo interesse por diferentes campos das linguagens da arte, especialmente o cinema e a literatura levaram-no a incorporá-las, em suas obras, em citações diretas ou variantes paródicas, obtendo resultados muito originais.

Dentre as temáticas que aparecem com insistente frequência, figura, nos seus escritos, a Polinésia dos romances de aventura de Joseph Conrad, Sommerset Maugham, das viagens imaginárias que fazia desde a infância. Mais que fonte de inspiração, estas sagas vieram a contribuir para a edificação de um pensamento original sobre composição musical e suas interfaces com outras formas de expressão artística.

Em que medida tais elementos do imaginário do compositor se consubstanciaram em sua obra? Até o momento parece ainda não haver estudos a respeito. á vários escritos esparsos do próprio Mendes que se referem aos modos pelos quais se dá a transposição intersemiótica de um Havaí iconizado, por meio das linguagens cinematográfica e literária, nas suas composições. Como detalha o compositor, o arquipélago foi musicalmente concebido pelos compositores germânicos atuantes em Hollywood, na década de 1930. Que traços formais representam essa Polinésia e de que maneira foi absorvida por Gilberto Mendes?

Antes de prosseguir, vale observar que a Polinésia é um signo em mutação e sempre reinventado: se no século XXI é turismo de "baladas" e "luais", na década de 1950 estabeleceu um modo de vida, criando hábitos cotidianos, no âmbito da denominada cultura tiki pop. A paisagem sonora aqui é tecida por Martin Denny, epígono dessa "onda".

1 Dentre as obras mais conhecidas, destacam-se nascemorre (sobre poema de Haroldo de Campos, 1962); Santos Football Music (1965), Motete em ré menor (1966, sobre poema de Décio Pignatari), cidade cité city (1965), Asthmatour (1971, sobre texto de Antônio José Mendes). Nessas obras, o compositor introduziu a transmissão radiofônica (Santos Football Music), elementos da linguagem publicitária: o Motete se inspirou na dinâmica dos letreiros luminosos noturnos; Asthmatour, introduz slogans falados e um jingle ao final. cidade cité city mescla aparelhos eletrodomésticos e, em particular, toca-discos e rádio, em que se põem a ouvir peças de Roberto Carlos, iê-iê-iê e outros hits da época em que foram compostas. Um estudo detalhado dessas obras se encontra em VALENTE (1997) 
Que traços característicos a definem? O que há de comum entre o Havaí pop/art-déco de Mendes e o tiki pop de Denny?

\section{A música da Broadway e o lied moderno norte-americano: entre os clássicos e os standards}

Antes de tratar do envolvimento de Gilberto Mendes com a música "havaiana", faz-se necessário esclarecer em que categoria ela se insere. Partindo da conceituação estabelecida pelo compositor, ela se encontra como uma ramificação da música popular urbana, de natureza híbrida: é o caso da canção estadunidense das décadas de 1930-40. Segundo Mendes, equipara-se, sob o aspecto formal, à música de concerto: "Esse lied norte-americano constitui um momento 'especialíssimo', tão relevante quanto a Idade Média dos troubadours e dos minnesingers" (MENDES, 1999, p. 16). Na sua versão para os musicais de Hollywood, foi eternizado pelas vozes de Fred Astaire, Ginger Rogers, Bing Crosby, Dorothy Lamour, Dick Powell, Rudy Vallee, Alice Faye. Sendo de natureza híbrida, remete, simultaneamente, a todos os componentes que lhe deram origem. Mendes encontra, numa mesma obra

(...) o eco da alegria vienense, o clima rarefeito bávaro-tirolês, subitamente o envolvimento pela nostalgia russo-judaica; o ponto final, identificador, de estranhos caminhos que vêm do Volga e do Danúbio, dos Alpes às praias do Havaí, passando por Nova lorque e Los Angeles, 'road to Singapura'..." ([1984]2014, p. 75-76).

Essa música que o compositor classifica como "impura" será objeto de seu interesse desde a juventude: as big bands, as trilhas de cinema, os clássicos do cabaré alemão. Os signos da cultura midiática constituem matéria-prima para as composições de Mendes, aparecendo claramente em várias obras, de forma paródica ou, mais raramente, como citação direta. De que maneira essa temática se manifesta musicalmente? Para entender mais claramente essa referência, faz-se necessária uma breve visita à Polinésia engendrada pelo cinema da década de 1930 que, juntamente com a literatura, deu os contornos a um paraíso imaginário muito explorado na arte e no entretenimento.

\section{O Havaí hollywoodiano: um sonho de consumo (não tão) distante, em suaves prestações}

Mais que um laboratório de experimentação de uma linguagem híbrida que surgia, Hollywood foi responsável pela criação de conteúdos que orientaram o imaginário social, especialmente no período compreendido entre Guerras. Some-se o fato de que os avanços tecnológicos promoveram um rápido desenvolvimento das linguagens audiovisuais; a cinematográfica, particularmente. 
Os compositores serão de capital importância, por criarem um código dotado de uma gramática específica própria, viabilizando a construção da narrativa (música incidental), assim como a formulação de um modelo de canção-tema, destinada a tornar-se produto vendável, no formato disco: "Do mesmo modo que atraem os melhores escritores, os estúdios organizam, desde os anos 1930, departamentos musicais muito estruturados para os quais é contratada a fina flor dos compositores, músicos e outros especialistas." (NACACHE, 2013, p. 95). E a música dos filmes de Hollywood é componente essencial da narração fílmica, desde os primórdios do cinema sonoro:

\begin{abstract}
A influência da música lírica e sinfônica de finais do século XIX, e em particular o modelo wagneriano, é evidente: os compositores dos estúdios, maioritariamente oriundos da Europa - Erich Wolfgang Korngold, Max Steiner, Franz Waxman, Dimitri Tiomkim - conhecem e praticam a arte da composição figurativa, modelada da narrativa. O gosto destes torna-se norma de Hollywood: longas linhas melódicas, poderosas massas orquestrais, continuum musical que reflete fielmente a banda-imagem (NACACHE, 2005, p. 96).
\end{abstract}

A semântica constituída pela trilha sonora será um forte aliado na construção do imaginário que, aliado ao turismo, enquanto consumo do tempo livre, cresce como serviço turístico ${ }^{2}$. Voltado a uma cultura de massa, após a II Guerra Mundial, as facilidades de comunicação e transporte fomentarão o turismo sensivelmente.

Em assim sendo, faz-se imperativo retomar o clássico Cultura de massas no século XX, de Edgar Morin (1962). O texto destaca a cultura do lazer, produto da redução da duração do tempo de trabalho doméstico, ampliando, assim, o tempo disponível para outras atividades (MORIN, 1969, p. 71-73). Este tempo livre será largamente ocupado pelas viagens de fim de semana e pelas férias (MORIN, 1969, p. 77).

Como atividade inserida no âmbito daquilo que veio a denominar-se como cultura de massa, o turismo transforma-se em consumo: de quilômetros, comidas, rituais, locais. O turista percorre, adquire; recolhe as reminiscências da experiência, sob a forma de bugigangas, os souvenirs. (MORIN, 1969, p. 78).

As agências de turismo venderão "pacotes" incluindo elementos de imaginário, consubstanciados em objetos materiais, como o DVD dos passeios e noitadas; o visitante guardará de suas andanças "cápsulas de memória" 3 , muitas delas musicais:

2 Os filmes de aventura, particularmente, despertarão interesse pelas viagens aos mundos desconhecidos e "selvagens", promevendo a indústria do turismo.

3 Denominamos cápsulas de memória signos que se sedimentam na memória pessoal ou coletiva, capazes de evocar, de maneira imediata, sentimentos e sensações, assim que acionados. No caso da música, tais signos são dotados de alto poder semântico. Assim é a canção que marcou "o primeiro beijo", como também aquelas que remetem a eventos patrióticos, esportivos: Coração de estudante, como hino das diretas-já; O povo unido, jamais, será vencido, de Sergio Ortega, passou por várias apropriações, relacionado sempre a protesto cívico. Sobre o tema, uma abordagem bastante ampla se encontra em VALENTE (2003). 
os repertórios "típicos", "locais" (especialmente de restaurantes) comporão o álbum de "cartões postais sonoros"

\section{A Polinésia hollywoodiana de Dorothy Lamour e de Don, The Beachcomber}

Gilberto Mendes sempre mostrou entusiasmo por temas relativos à Polinésia. Isso está patente não apenas nas suas crônicas, na sua obra; era assunto frequente em conversas informais entre amigos. Uma revista de viagem cuja matéria de capa lançada poucos meses antes da sua morte - "Viva o 'American dream': Havaí e Califórnia" - imediatamente a curiosidade chamounos a atenção. Procuramos apurar do que se tratava ${ }^{5}$ e levamos ao conhecimento do compositor. ${ }^{6}$

Mendes teve, enfim, a oportunidade de conhecer o Havaí, já em idade avançada. Em Honolulu, reconhece os clichês que a revista enaltece, mas também os "cartões postais sonoros" de outros tempos, volta e meia presentes em seus escritos, como reminiscência prazerosa:

Por toda Honolulu se ouve Blue Hawaii, ainda hoje. Virou uma espécie de hino da cidade. Honolulu é também o nome de mais um outro emblemático filme, com a espetacular sapateadora Eleanor Powell. Tommy Dorsey gravou a canção-título, que tem no final a marca melódica da música havaiana feita em Los Angeles por descendentes europeus com os ouvidos ainda ligados à música tirolesa e ao cromatismo wagneriano (MENDES, 2008, p. 29-30).

É de se averiguar se a fugacidade com que as excursões mais recentes proporcionam em lembrança viva da experiência, tal como ocorreu com o compositor. Ainda assim, acreditamos que as peças musicais, devido à sua forte capacidade de evocar memórias - justamente porque se associam a sentimentos e estados d'alma - ainda tenham poder de pregnância na memória?.

Para além do ícone que sempre fascinou Gilberto Mendes, outra etapa marcante, um fenômeno marcante da cultura de massa pequeno-burguesa estadunidense marcaria época, na década de 1950 - a cultura tiki pop - transfigurando, uma vez mais, a paisagem sonora (e imaginária) da Polinésia.

4 Denominamos "cartões postais sonoros" componentes da paisagem sonora (SCHAFER, 2002), com destaque para as obras musicais e, em particular, canções. Tais como retratos que se fixam em fotografias, há canções que fazem referência imediata, especialmente a cidades: Garota de Ipanema, O sole mio, New York, New York, Mi Buenos Aires querido, Foi Deus estão relacionadas indissociavelmente às cidades do Rio de Janeiro, Nápoles, Nova lorque, Buenos Aires, Lisboa. Ess3e tema foi analisado mais detalhadamente em VALENTE (2007).

5 A chamada para a matéria anuncia: "Havaí: é tudo verdade: As ondas enormes, o pôr do sol dourado, as camisas floridas... Os clichês havaianos são deliciosamente autênticos. Mas é só circular pelo fabuloso arquipélago que você vive, e entende seu grande atrativo: o mágico e encantador espírito de aloha" (LESSA, 2015, p. 31, grifos nossos). Seguem descrições sobre o local , com "corpo e alma de paraíso tropical"; os habitantes, com a "cor do pecado", olhos escuros e rasgados (LESSA, 2015, p. 32). A viagem deve coroar-se com um "luau": o pôr do sol, "recheado de danças, músicas, comidas típicas, como o porco cozido sob a terra" (LESSA, 2015, p. 44).

6 Acreditamos que este tenha sido o último "debate" sobre o tema.

7 Nos últimos anos, o viajante pode levar consigo uma coletânea que standards característicos do local visitado, registrados no seu smartphone. Em contrapartida, uma maior quantidade de obras, sob a forma de "arquivos digitais" não implica em uma prática de escuta mais demorada ou atenta. 
As manifestações mais efetivas da presença da cultura polinésia na cultura de massa já se revelam na década de 1920, quando os Estados Unidos se entusiasmam com os artistas boêmios do final do século precedente, como Gauguin, Melville que, em seus relatos de viagem, descrevem sua saga ao penetrar destinos longínquos: Ilhas Galápagos, Marquesas, Taiti - os paraísos idílicos, marcados pela abundância: de comida, de natureza virgem, de mulheres seminuas ornadas de flores.

Na década de 1930, a Polinésia é absorvida pela indústria cinematográfica. Destacam-se as produções Power of love (Dreyer; Ruby/ Axte; Mendoza) e sua canção tema, White shadows in the south seas (Metro Goldwin-Mayer, 1928); O grande motim (Mutiny on the Bounty, 1935); O furacão (The Hurricane, John Ford, 1937). A canção The Moon Of Manakoora, interpretada por Dorothy Lamour, é a marca do longa-metragem.

A Polinésia ressurgiria no cotidiano estadunidense logo após a II Guerra Mundial, quando a figura totêmica do deus Tiki é prontamente adotada pelas estrelas de Hollywood como "modo de vida", traduzido por um hedonismo emoldurado: residir em loteamentos equipados com lagos artificiais e mini-vulcões; frequentar bares temáticos, "ambientados" no arquipélago; fazer coquetéis à beira da piscina, contornada com tochas de fogo... Essa moda duraria até inícios da década de 1960.

A cultura tiki da década de 1950 tem sua paisagem sonora (SCHAFER, 2002) característica e seu epígono responde pelo nome de Martin Denny, criador da música singular que animava os frequentadores do bar de Don, The Beach Comber, empresário pioneiro na concepção dos bares-restaurantes ambientados na temática tiki.

Denny concebeu, em 1957, a Hawaïan music, que inclui instrumentos de base tradicionais do combo de jazz, somados ao ukelelê, o "pássaro selvagem" - invento de Denny - asssobios, marimbas, metalofones, coro em vocalize, guitarra, atabaques. Esse conjunto de timbres, de modos performáticos e arranjos resultam em sonoridades que constituirão as tópicas musicais ${ }^{8}$ do paraíso distante e selvagem e que iconizam a cultura tiki pop da década de 1950. A lista de sucessos é extensa e responde por títulos curiosos: Exotica (1957) Primitiva; Forbidden Island (1958), Afrodesia (1959). Essa paisagem sonora selvagem servirá de arranjo para outros standards de todo o mundo:

8 A teoria das tópicas vem sendo desenvolvida, desde a década de 1980. Como esclarece Acácio Piedade: "as unidades musicais do discurso (motivos, frases, temas, padrões rítmicos, progressões harmônicas etc.), para além de seu papel funcional nos segmentos formais, muitas vezes apresentam qualidades semióticas a elas atribuídas, ethoï, o que ocorre na maioria das vezes por meio de convenção cultural (diga-se, histórica e tácita). Esse tipo de significação implícita se encontraria na progressão de posições de elementos na cadeia sintagmática de um discurso musical." Nos estudos de Ratner, tópicas clássicas encontram danças como minueto, estilos como música militar e de caça (hunt music), cantabile, pastorale, estilo culto (learned style), entre outros (...). As tópicas portam significados que são reconhecidos na sua época, se ligando também ao mundo literário, calcados em fortes aspectos socioculturais. Elas derivam de gestos convencionais e de gêneros familiares da comunidade que se situa na base da ação afetiva das tópicas, cobrindo a expressão de um mundo complexo de comunicação, fantasia e mito (PIEDADE, 2013, p. 8). 


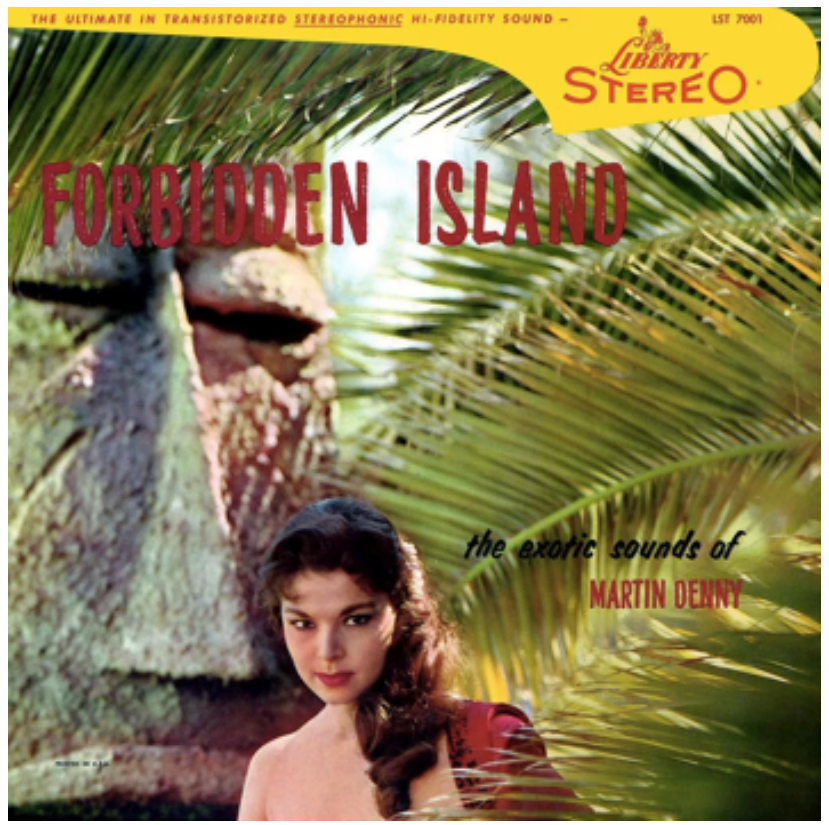

Fig. 1. Forbidden Island - capa do disco (LP) - O deus Tiki, à esquerda Fonte: https://pcover.wordpress.com/tag/martin-denny/page/2/

A sonoridade dessa música compõe-se de várias camadas multipistas sobre as quais se sobrepõem diferentes sons "tropicais": plena em reverberações, gera a sensação acústica de prolongamento das durações, o que é reforçado com os arpejos em profusão, sobrepostos. Trata-se, na verdade, de uma variante do pop polinésio (BUFFET; PALERMO; PERREAU, 2014, p. 34). E essa estética se espalhará em outras produções fonográficas de artistas provenientes de outras regiões ao redor do mundo, como a igualmente "exótica" Yma Sumac...

Não obstante a estilização forçada, alguns elementos da música polinésia autóctone serão mantidos: a música havaiana popularizou o glissando na guitarra, produzindo notas longas com vibrato- por meio da técnica do lap steel, ainda na década de 1920.

\section{De Viena aos Mares do Sul}

Como já antecipamos no início deste texto, o Havaí que sempre fascinou Gilberto Mendes é a música inventada pelos compositores germânicos de origem judaica para os estúdios de Hollywood: Frederich Holländer, Alfred Newman, Bernard Herrmann, na década de 1930. Esse Havaí não ressoa na produção de Martin Denny, da década de 1950-60 e tampouco remete à música nativa, praticada até a chegada dos missionários protestantes, em 1820: 
de predominância vocal; os instrumentos se limitavam a idiófonos e aerófonos de madeira e bambu; a percussão, geralmente corporal, visava acompanhar a dança (AUBERT, 2005, p. 74) ${ }^{9}$.

O que se configurou como música havaiana, criada em Hollywood, constitui-se de um conjunto de estilemas característicos - as tópicas, que denunciam a formação acadêmica europeia de quem as concebeu - aqui, os rastros da música de Viena e Berlim dos fins do século XIX são inarredáveis: o cromatismo wagneriano desembocou no Expressionismo musical e em derivações da música popular urbana, emergentes na Alemanha, nas primeiras décadas do século XX:

Compositores quase europeus, ou mesmo europeus, como Friedrich Holländer autor de Moonlight and shadows e Bronislaw Kaper, autor de Gone, like the wind you are gone, inventaram em Hollywood essa música de praia que não existe na música étnica de toda a Polinésia. Holländer vinha de Berlim, e em suas admiráveis canções americanas ecoa o cromatismo das kabarett Melodien, da Friedrichstrasse dos anos 20 e dos musicais da velha UFA (MENDES, 2008, p.31).

De certo modo, Holländer e seus parceiros de métier contribuiriam para aproximar o paraíso selvagem da "civilização", com base na experiência sensória: a escuta das canções e peças incidentais compostas para os filmes tornariam o cromatismo familiar, pelas canções. Por outro lado, o cromatismo, como música incidental endossaria o caráter "exótico". O arranjo, incorporando timbres da orquestra sinfônica ao instrumento característico - a guitarra, tocada em lap steel - ou a sua imitação, com o portamento das cordas sela a criação da tópica havaiana.

\title{
Saudades do Parque Balneário Hotel, em Waikiki
}

\begin{abstract}
Música é pura abstração, significa somente suas próprias estruturas. Mas o que significam suas estruturas? O que desejamos que elas signifiquem, mesmo porque todas as coisas que desejarmos que elas signifiquem, mesmo porque elas sejam. Nós podemos impor o seu significado, ou ela adquire um significado imposto pelo seu uso. Como também podemos dar à música um outro significado muito diferente daquele pretendido e imposto pelo seu autor (MENDES, 1994, p. 168).
\end{abstract}

Feito este tour, cabe-nos voltar ao porto de onde - a partir da leitura dos romances de aventuras - Gilberto Mendes espreitava os navios passarem e desenhava mentalmente suas rotas e destinos. A cidade de Santos sempre foi porto e passagem de todo tipo de embarcação: de submarinos nazistas, frota mercantil, transatlânticos de turismo...

9 As antigas danças narrativas hula e os cantos mele foram largamente suplantados por um gênero harmonizado a ocidental, caracterizado pela presença ocasional de um tipo de yodel evocando à antiga técnica local do falsete, denominada le ki'eki'. A guitarra, em sua variante havaiana, o ukelelê e o tambor tini (...) substituíram a maioria dos instrumentos tradicionais polinésios, dentre os quais se destaca o tambor com fenda, a concha marinha, a guimbarda e diferentes tipos de membranofones e flautas (AUBERT, 2005, p. 74). 
Essas experiências de vida se materializaram num imaginário que o compositor inscreveu formalmente em sua obra:

Não sei se está claro que não estou fazendo um relato de viagens. Estou falando da minha música, dos fundamentos de meu gosto musical, que foi se forjando, inicialmente, ao som dessa música realmente americana, de cinema, feita numa Los Angeles com os olhos em Honolulu (MENDES, 2008, p. 33).

O "Havaí" do compositor santista surge, pois, de um diversificado leque de elementos aparentemente discrepantes e incompatíveis, como mosaicos justapostos e contíguos, como se pode verificar estudando as partituras, mas sobretudo pela escuta atenta. Aliás, os títulos já sinalizam esse procedimento composicional, senão vejamos: Ulisses em Copacabana surfando com James Joyce e Dorothy Lamour (1988), ou: Um estudo?... Webern e Eisler caminham nos mares do sul (1989).

Como a música "polinésia" se manifesta, nessas obras? De maneira fragmentária, obedecendo à técnica que o compositor adota, na década de 1980, quando passa a misturar, numa mesma obra, gestos retóricos de estilos tão distintos entre si, como do serialismo, minimalismo, bossa-nova, foxtrote, cabaré alemão e a música "havaiana". Para Antonio Eduardo Santos, estudioso da obra de Mendes, as peças declaradas "havaianas" se encontram na fase que ele classifica como de "Trans-Formação", marcadas por uma sintaxe que aponta para “(...) uma literatura onde o piano apresenta atitudes ao mesmo tempo comprometidas e libertas, com evasão para a intuição pura e para a possibilidade de uma revolução permanente" (SANTOS, 1997, p. 128).

Segundo Rodolfo Coelho de Souza, Mendes faz uso recorrente da construção poética por parataxe: verifica-se uma “(...) apropriação, pelo compositor, de referências estilísticas muito díspares entre si que entretanto compõe um painel sonoro no qual é possível encontrar uma intrigante unidade de sentido" (SOUZA, 2007, p. 83). O caráter fragmentário, em vários momentos, mescla camadas sobrepostas,

coexistindo no tempo como se diversas músicas soassem simultaneamente, cada uma delas com sua lógica própria, mas associadas num todo de caráter dançante, em estilo de bossa-nova, que aparenta ter uma sintaxe direcional que entretanto é desmentida pelas contradições internas da retórica turbulenta que se forma pelo acúmulo das superposições e justaposições concebidas pelo compositor (SOUZA, 2007, p. 85).

Em outras palavras, poderíamos dizer que o "Havaí" (assim como todos os componentes) se apresenta como uma reformulação, segundo o modo de ouvir e sentir tecidos musicais e paisagens sonoras que, por sua vez, são oriundos das trilhas sonoras compostas para o cinema de 1930 e que repercutiam na memória do compositor. Para citar um exemplo, em Vento Noroeste (1982), combinam-se fragmentos dos Estudos op. 25, 
$n^{\circ} 6$ e op. 10, $n^{\circ} 1$ de Chopin, além de referências a Schumann, Liszt (Au bord d'une source), Debussy (Prelúdio op. 28, nº 8radus ad Parnasum, Jardins sous la pluie), Barquinho, de Menescal, as harmonias de Holländer (SANTOS, 1997, p. 89-98).

Já em Um estudo?... Mendes reaproveita o mesmo material de Ulisses em Copacabana... com "(...) uma cadência havaiana, à maneira hollywoodiana" (SANTOS, 1997, p. 117), como se pode observar nos seus últimos acordes:

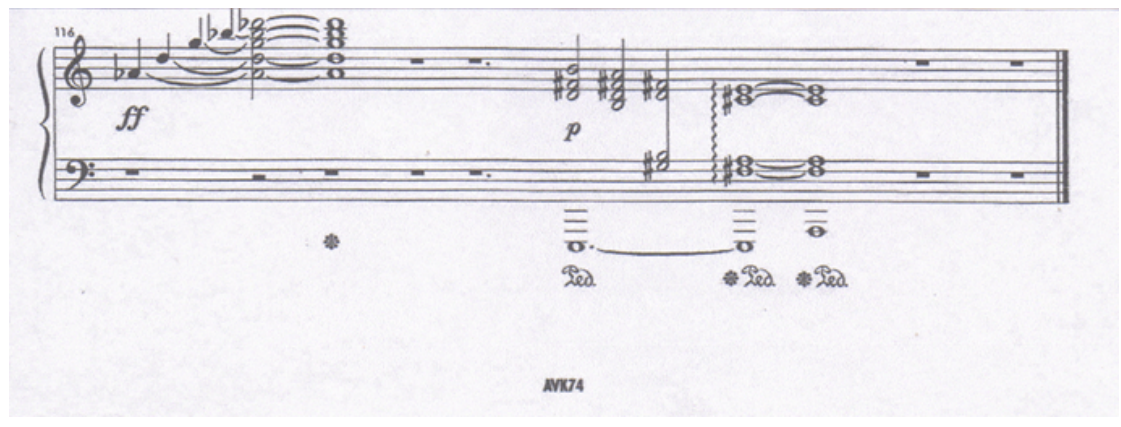

Fig. 2. Um estudo?... Webern e Eisler caminham nos mares do sul. Fonte: partitura. Alain Van Kerchkhoven, p. 3.

Outra observação acerca do período de Trans-Formação é que esta coincide com o período em que o compositor avançava os 60 anos de idade e passava a revisitar vários temas que Ihe foram caros, especialmente na sua juventude: os musicais da década de 1930, o foxtrote, Dorothy Lamour... Acreditamos que, nesse momento, ele estaria acionando cápsulas de sua memória (VALENTE, 2003) que guardaram momentos felizes de suas experiências pregressas, evocadas sob a forma de poética criativa. Em um dos últimos registros filmados, afirmou:

Morava num lugar muito paradisíaco, na ponta da praia, em Santos, no começo da década de 40, era um Havaí! Uma beleza indescritível, uma beleza de mar... (...) Meus mares do sul, meu Havaí... Demoraria tantos anos para eu ir ao Havaí, um dia... E eu acabei indo, um dia... Mas eu já tinha o meu Havaí... (MENDES, 2012).

E, depois de, finalmente, ter visitado Honolulu, observou:

Aquele bar ao ar livre de um velho hotel de luxo à beira-mar me fez pensar no grill de verão do Parque Balneário Hotel, de minha cidade. Saudades do Parque Balneário Hotel! Fui reencontrá-lo ali, em Waikiki. Enquanto bebia sucos de frutas, nativos tocavam guitarras havaianas e ukuleles, uma jovem cantava e dançava a hula hula, e eu me transportava para os meus treze anos, quando ouvia Lani McIntire and his Hawaiians tocando Sweet Leilani, pela Rádio Clube de Santos (MENDES, 2008, p. 29-30). 
De fato, como o compositor afirma, música é abstração e "não significa nada", além das suas estruturas... Mas podemos designar-Ihe algo para além de seus elementos formais, significados, convenções impostas pelo hábito, porque desejamos que assim o seja. Honolulu se situa no Trópico de Capricórnio, na morna Santos!

\section{Com Dorothy Lamour, sob o luar de Manakoora...}

Há vários anos estudamos o papel da música nos processos comunicativos; suas formas de expressão poética. Interessa-nos entender como são construídas as diversas "trilhas sonoras", playlists, "álbuns", "coletâneas" - ou outro nome que se venha a dar para estas coleções de repertórios musicais; ainda, desvendar como tais coleções formam "cápsulas de memória" de maior ou menor permanência (VALENTE, 2003). Repertórios musicais constituem importante componente na memória das culturas, uma vez que a presença desses signos caracteriza não apenas a paisagem musical cotidiana das pessoas comuns, mas a própria cultura, em sua expressão particular.

A música deixa os seus rastros nas produções que surgiram, ao longo dos séculos, em unidades discretas: no andamento, na duração, nas formulações rítmicas, nos timbres... Ao fim e ao cabo, as relações que o tempo musical dita são coerentes com a evolução da paisagem sonora - que é movente, por natureza. Os mesmos três minutos de Dorothy Lamour entoando The Moon of Manakoora evocarão experiências sensórias, emotivas e intelectuais distintas daquelas proporcionadas pela escuta do Similau, de Martin Denny.

Sob a inspiração de Gilberto Mendes, o desenvolvimento deste texto procurou apresentar, inicialmente, como a temática "havaiana" participou do seu processo composicional. Ao investigar o tema de perto, deparamo-nos com outros desdobramentos, como as formas de apropriação do imaginário polinésio pela indústria cinematográfica, a ponto de transformar em estilo de vida, na década de 1950 e destino turístico de tendência hippie.

Na obra de Gilberto Mendes, a Polinésia revela uma convergência de experiências estéticas: a leitura de romances de aventura situados nos Mares do Sul; a estética musical vienense, dos finais do século XIX que desaguaria, mais tarde, na neue musik. Da mesma forma, a canção popular estadunidense, é igualmente herdeira da estética germânica. Na escritura muito peculiar do compositor santista, esses temas e essas linguagens estéticas se misturam a vários outros, em construções poéticas por parataxe.

No entanto, de "havaiano", propriamente dito, parece não haver uma obra com traços integralmente característicos. Em outras palavras, o Havaí de Gilberto Mendes permanece música... wagneriana, alemã!

Resta-nos enfatizar, como palavras finais, que as relações entre meio-ambiente e trilhas sonoras pleiteiam estudos mais vigorosos e consistentes. Ainda que alguns estudiosos nas áreas interdisciplinares entre música e audiovisual tenham se debruçado sobre 
o tema - como Murray Schafer e Michel Chion, os liames entre turismo musical, "cartões postais sonoros" e uso publicitário ainda parecem pouco explorados. Uma proposta de continuidade que nos parece prolífica reside no mapeamento das formas de manifestação da linguagem musical, por meio de repertórios específicos, gêneros musicais e respectivos períodos históricos.

No presente caso, urge analisar em detalhe as diversas implicações que ocorreram entre as várias manifestações, das décadas de 1920-60, na cultura midiática estadunidense, assim como suas formas de circulação, apropriação, tradução intersemiótica (dentre tantas) pelas culturas em que ela se arraigou. $\mathrm{O}$ impacto da cultura tiki pop estadunidense na paisagem sonora local (por mais de uma década), bem como suas repercussões internacionais, é um exemplo. Para além dos clichês assimilados pelas festividades carnavalescas, que elementos terão permanecido? Algo dessa paisagem sonora se extrai, além da guitarra em lap steel?

Decifrar como os processos tradutórios do próprio código operam, desdobrando-se em outros signos, constitui tarefa ao mesmo tempo difícil e sedutora, pois, como destaca Lúcia Santaella, o signo não pode ser a coisa que ele designa: "Fica sempre um resíduo, uma sobra, algo restante que o signo não pode recobrir desde o nível de descolamento mais radical entre o signo e o referente, só unidos por força de uma convenção" (SANTAELLA, 1996, p. 44).

Isso Gilberto Mendes demonstrava conhecer com proficiência. A lua de Manakoora enche a noite, com os mágicos encantos polinésios. E Dorothy Lamour, em sua vocalidade, embala a noite.

Heloísa de Araújo Duarte Valente é professora do PPG de Comunicação da Unip.

whvalent@terra.com.br

\section{Referências}

90 ANOS, 90 VEZES GILBERTO MENDES. Disponível em: <https://www.youtube.com/watch?v=sa AGUgx3w5A\&list=PL08882815878609A0\&index=14>. Acesso em: 28 jan. 2016.

BUFFET, A.; PALERMO, B.; PERREAU, Y. Tiki pop I'Amérique rêve son paradis polynésien. Paris: Beaux Arts; TIM Éditions. Issy-les-Moulineaux (França), 2014.

LESSA, K. "Havaí: é tudo verdade". In: Viaje mais, São Paulo, n. 168, maio 2015.

LP COVER ART. Disponível em: <https://pcover.wordpress.com/tag/martin-denny/page/2/>. Acesso em: 28 jan. 2016.

MARTIN DENNY. Disponível em: <http://www.britannica.com/biography/martin-denny>. Acesso em: 28 jan. 2016.

MENDES, G. "A música". In: CAMPOS, A. (org.) O balanço da bossa. São Paulo: Perspectiva, 1984. 
. Uma odisseia musical: dos Mares do Sul à elegância pop/art-déco. São Paulo: Edusp/Giordano, 1994. Viver sua música. Com Stravinsky em meus Ouvidos, Rumo à Avenida Nevskiy. Santos: Realejo; São Paulo: Edusp, 2009.

Um estudo? Eisler e Webern caminham nos Mares do Sul... Partitura: piano solo. Bruxelas: Alain Van Kerckhoven, 1997.

MORIN, E. Cultura de massas no século XX- o espírito do tempo. Rio de Janeiro: Forense, 1969

NACACHE, J. O cinema clássico de Hollywood. Lisboa: Texto \& Grafia, 2012.

PERREAU, Y. Gloire et désuétude du cinéma tiki: Une usine à fantasmes pour Hollywood. In: Tiki pop I'Amérique rêve son paradis polynésien. Paris: Beaux Arts; TIM Éditions. Issy-les-Moulineaux (França), 2014.

PIEDADE, A. T. A teoria das tópicas e a musicalidade brasileira: reflexões sobre a retoricidade da música. In: El oído pensante, vol. 1, n. 1, 2013. Publicado em: http://ppct.caicyt.gov.ar/index.php/ oidopensante/article/viewFile/2202/1982. Acesso em: 26 jan. 2016

SANTOS, A. E. Antropofagismo na obra pianística de Gilberto Mendes. São Paulo: Annablume; FAPESP, 1997.

SCHAFER, R. M. A afinação do mundo. São Paulo: Edunesp, 2001.

SOUZA, R. C. Sintaxe e parataxe na música moderna e pós-moderna. In: Opus. Goiânia, v. 13, nº 2, p. 73-91, dez. 2007.

VALENTE, H. A. D. Os cantos da voz: entre o ruído e o silêncio. São Paulo: Annablume, 1997.

. As vozes da canção na mídia. São Paulo: Via Lettera; FAPESP, 2003.

"Canção artística, canção popular, canção das mídias: movência e nomadismo". In: VALENTE

(org.). Música e mídia: novas abordagens sobre a canção. São Paulo: Via Lettera; FAPESP, 2007.

Texto recebido em novembro de 2016

e aprovado em agosto de 2017. 